\title{
Asalto a la razón: estrangulamiento de la universidad pública
}

\section{HUMBERTO MÁRQUEZ COVARRUBIAS}

La educación pública es un derecho humano fundamental que debe ser tutelado por el Estado. Sin embargo, en México la exclusión social y educativa se manifiesta como uno de los saldos negativos del proyecto neoliberal que pretende mercantilizar bienes públicos y comunales. Los gobiernos restringen el presupuesto amparados en la prédica de la austeridad, que en la práctica reduce recursos para el desarrollo humano y transfiere sumas considerables al sector privado. Mientras que las universidades públicas reciben recursos insuficientes, avanza progresivamente la lógica empresarial y se profundiza la deuda social del Estado. Pese a ello, las comunidades universitarias se movilizan para resistir la contrarreforma neoliberal y proponen modelos educativos alternativos.

*Docente investigador de la Unidad Académica de Estudios del Desarrollo, Universidad Autónoma de Zacatecas.

\section{Abrogación de derechos}

Empecinado en abrir espacios de valorización a los grandes capitales, el proyecto neoliberal vulnera el basamento material de la reproducción de los pueblos: las tierras les son despojadas para instalar economías de enclave rentistas; el mercado laboral se precariza con el propósito de ofrecer fuerza de trabajo barata y desorganizada; la red de protección social del Estado se desmantela y se abre al mercado; y el conjunto de derechos sociales y laborales producto de conquistas históricas se vulnera para crear un clima de «competitividad» y garantizar los márgenes de rentabilidad exigidos por las corporaciones.

En ese concierto, la educación pública está siendo atacada a fin de deteriorar su condición de derecho humano y convertirla en un espacio mercantil donde la educación y el conocimiento se presentan como mercancías en lugar de figurar como bienes públicos. Lentamente, la contrarreforma se aplica en los distintos niveles educativos con varias políticas: recorte al financiamiento público, precarización del trabajo académico y desvalorización de perfiles laborales de egresados de los planteles educativos.

\section{Austeridad}

La agenda neoliberal constriñe el presente y el futuro de la educación superior al tema del financiamiento. Como si la educación pública fuera un asunto semejante a la administración de un negocio, la palabra «crisis» se aplica a las universidades cuando el Estado canaliza recursos insuficientes a sabiendas de que las instituciones caerán en insolvencia, al extremo de no poder cubrir los gastos más elementales -salarios, prestaciones, mantenimiento-; ello en detrimento de la 
misión social de brindar educación gratuita y de calidad, no sin acumular deudas e incubar conflictos internos, dentro de una espiral en la que los comentaristas oficiosos se mofan de las instituciones educativas como si fuesen un «barril sin fondo».

En el cumplimiento de su misión social, uno de los principales obstáculos de la universidad pública deviene del régimen de «austeridad» decretado unilateralmente por el Estado. La restricción del gasto social sigue la receta del ajuste neoliberal que recorta recursos a la educación y también a la alimentación, la salud, la vivienda, el transporte y otros rubros. Empero, el Estado reserva y canaliza grandes cantidades de recursos públicos en beneficio del sector privado. De forma preponderante privilegia los intereses del capital financiero con el pago oportuno de la deuda externa ${ }^{1} \mathrm{y}$ favorece a las elites empresariales con las privatizaciones, las inversiones público-privadas, los recurrentes programas de rescate, entre otros mecanismos.

\section{Cicatería}

No existe una política de Estado en materia educativa, que además de integral y de largo plazo garantice la educación pública, gratuita y de calidad. Son los ciclos políticos y las exigencias del capital financiero los que marcan la pauta.

${ }^{1}$ El pago preferente de deuda externa conlleva al Estado mexicano a recortar el gasto en educación, salud y otros rubros de desarrollo social. Para educación se contemplan 265 mil 704.2 millones de pesos en 2017, menos de 10.6 por ciento que el año anterior. Al pago del costo financiero de la deuda se destinarán 568 mil 197.6 millones de pesos que cubrirán la deuda externa e interna, los pasivos de Petróleos Mexicanos (Pemex) y la Comisión Federal de Electricidad (CFE), junto con el lastre del rescate bancario de 1995 (Fobaproa, ahora IPAB); esta partida supera el presupuesto combinado de educación, salud, desarrollo social e instituciones federales de educación superior (556 mil 41.1 millones de pesos). Roberto González, «Intereses de deuda pública superan el gasto social, en educación y salud», La Jornada, 11 de septiembre de 2016.

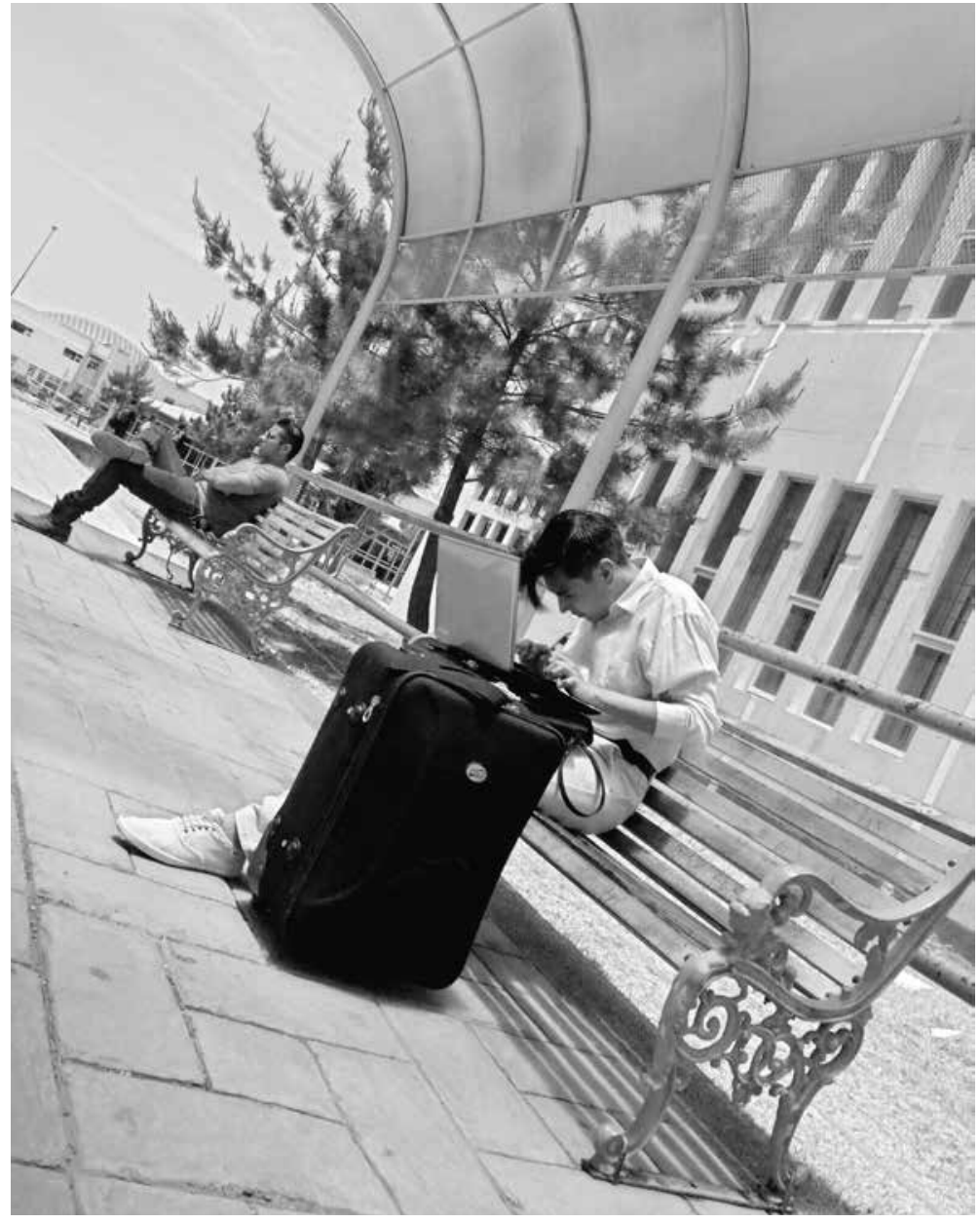

En general, la educación pública padece raquitismo por la decisión del Estado de ejercer un gasto bajo. Pese a que la norma constitucional (artículo 25) establece un mínimo de 8 por ciento del producto interno bruto (PIB), se destinan recursos por debajo de ese umbral (por ejemplo, en 2015 apenas 5.2 por ciento). Esto en el contexto de una supuesta «reforma educativa» en los niveles básicos, donde tampoco se han incrementado de modo significativo los recursos financieros. De modo particular, dicha política es lacerante para la educación superior, porque en ese nivel se invierte una porción equivalente a 1.3 del PIB. ${ }^{2} \mathrm{El}$ gasto por estudiante en México es de los más bajos en la clasificación de la Organización

\footnotetext{
2 Organización para la Cooperación y el Desarrollo Económicos (OCDE), Panorama de la Educación: Indicadores de la OCDE, París, OCDE, 2015.
}

La agenda neoliberal constriñe el presente y el futuro de la educación superior al tema del financiamiento. Fotografía: Jorge Vázquez 
para la Cooperación y el Desarrollo Económicos (OCDE): se gastan 8 mil 100 dólares por estudiante al año en educación superior, cuando el promedio de la OCDE es de 15 mil dólares. ${ }^{3}$

El financiamiento describe movimientos erráticos, en algunos tramos pareciera sostenerse y en otros se desploma, pero siempre en el umbral de insuficiencia. Los altibajos ocasionan severos trastornos en las universidades y la tendencia es un decremento en el gasto por alumno. Con el objetivo de armar el rompecabezas presupuestal cada año, las negociaciones políticas están anegadas por la incertidumbre y la improvisación. Los condicionamientos externos penden como una espada que amenaza con truncar la estructura universitaria y, lo más importante, vulneran las capacidades institucionales para ofrecer educación gratuita y de calidad a las clases populares.

La insuficiencia e inconsistencia presupuestales producen déficits crónicos en las universidades públicas que se muestran incapaces de alcanzar un nivel de cobertura que dé cabida a los estudiantes que demandan espacios. La exigencia de incluir a más alumnos en las universidades sin generar las condiciones mínimas para atenderlos a la postre deteriora el desempeño institucional, pues tienen que trabajar con los mismos o menores recursos que los años previos.

\section{Deuda social del Estado}

En términos formales, la obligación constitucional del Estado mexicano es garantizar la educación pública, gratuita y de calidad. En la realidad, el Estado neoliberal ha contraído una enorme deuda social, que no se reconoce, al excluir progresivamente a la población de los servicios educativos. Dirige enormes recursos al pago del capital financiero que medra con una deuda externa que es ilegítima e impagable.

${ }^{3}$ Idem.
Los signos de la deuda social educativa son múltiples. En general, el rezago educativo afecta a 32 millones de personas mayores de 15 años, de las cuales todavía son analfabetas 5.4 millones, ${ }^{4}$ no han concluido la primaria $10 \mathrm{mi}-$ llones y dejaron inconclusa la secundaria 16.4 millones. ${ }^{5}$ El perfil de escolaridad promedio es de 9.1 años para 2015, equivalente a la secundaria concluida. ${ }^{6}$ Este nivel educativo es muy bajo si se quiere disponer de una población educada en ciencias, tecnología, ética, civismo, humanidades, filosofía, política, cultura y artes, es decir, en las formas de pensamiento y las actividades humanas más representativas del mundo actual.

La trayectoria escolar se decanta por el tobogán de la exclusión, conforme avanzan los niveles se estrecha la cobertura. Desde la óptica de la cobertura educativa, a la primaria ingresa 98.5 por ciento de los niños; a la secundaria, 85.7 por ciento de los adolescentes; al bachillerato 53.1 de los jóvenes, y a la educación superior sólo 25.3 por ciento de los jóvenes. ${ }^{7}$ No obstante, el rezago y el abandono escolar marcan

${ }^{4}$ El analfabetismo pareciera erradicado. En 1970 la población analfabeta era de 7.7 millones de mexicanos (23.7 por ciento), para 2010 eran 5.4 millones de analfabetos mayores de 15 años (6.9 por ciento), más de la mitad eran mujeres e indígenas. Instituto Nacional de Estadística, Geografía e Informática (INEGI), Estadísticas históricas de México, 2010; Instituto Nacional de Estadística, Geografía e Informática (INEGI), Censo de Población y Vivienda, 2010. Más de medio millón son jóvenes entre 15 y 29 años, y poco más de 2 millones tienen entre 30 y 59 años. José Narro y David Moctezuma, «Analfabetismo en México: una deuda social», Realidad, datos y espacio, vol. 3, núm. 3, 2012.

${ }^{5}$ José Román, «Reducir 7.5 millones de personas con rezago educativo, meta sexenal del INEA», La Jornada, 29 de marzo de 2015.

${ }^{6}$ Las desigualdades regionales son evidentes: los estados con mayor pobreza también muestran el menor nivel educativo: Michoacán, Guerrero, Oaxaca y Chiapas; en contraste, la Ciudad de México, Nuevo León y Sonora presentan los mejores niveles, aunque el mayor (11.1) no es muy elevado, equivale al segundo año de preparatoria. Instituto Nacional de Estadística, Geografía e Informática (INEGI), «Escolaridad», 2015, http:// cuentame.inegi.org.mx/poblacion/escolaridad.aspx?tema $=\mathrm{P}$ ${ }^{7}$ Secretaría de Educación Pública (SEP), «Estadísticas del sistema educativo mexicano, Ciclo escolar 2015-2016», 2016, http://www.snie.sep.gob.mx/estadisticas_educativas.html 
El tobogán de la exclusión educativa sigue su marcha.

Por cada 100 niños que ingresan a la primaria:

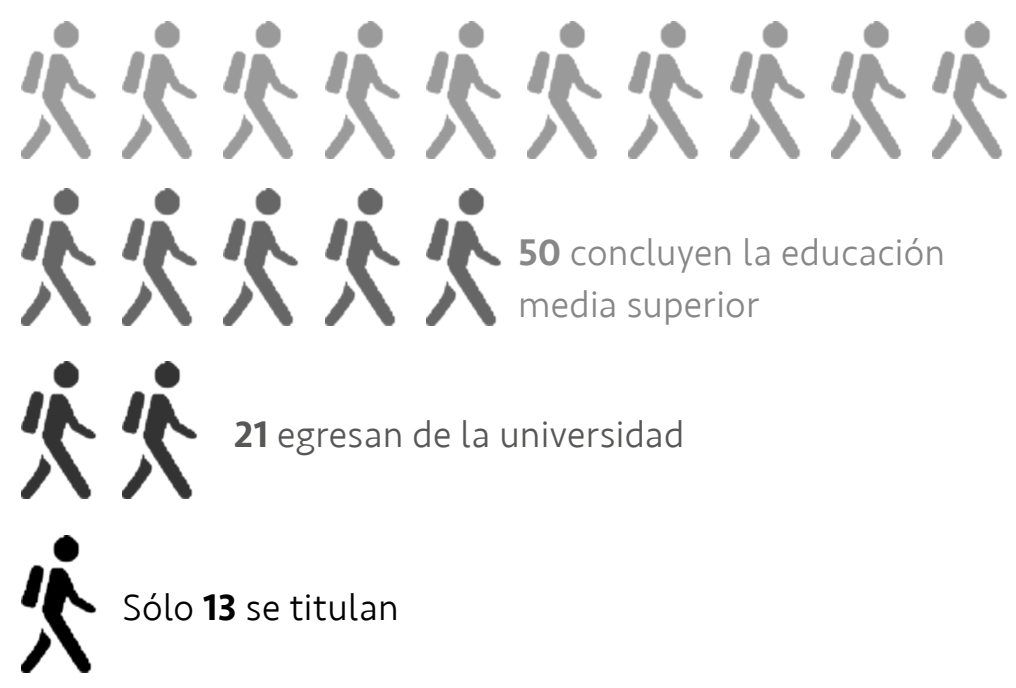

las trayectorias escolares: en promedio por cada 100 niños que ingresan a la primaria, 50 concluyen la educación media superior, 21 egresan de la universidad y sólo 13 se titulan. ${ }^{8}$

\section{Generaciones perdidas}

Si bien México ostenta la undécima economía del mundo, la cobertura universitaria es inferior a la de los países desarrollados, incluso a la de los subdesarrollados. En América Latina y el Caribe, la región más desigual del mundo, algunos países muestran altas tasas, como Cuba (95 por ciento), Puerto Rico (86 por ciento), Venezuela (78 por ciento) y Argentina (71 por ciento). El promedio de la región es de 41 por ciento, pero México ni siquiera se aproxima a ese nivel, registra una cobertura de 32 por ciento, ${ }^{9}$ apenas por arriba de países centroamericanos como Guatemala, El Salvador y Honduras. ${ }^{10}$

\footnotetext{
${ }^{8}$ Rodolfo Tuirán, «Los jóvenes mexicanos: situación actual y desafíos», conferencia dictada en la Facultad de Psicología, Universidad Nacional Autónoma de México, Ciudad de México, 2011.

9 Senado de la República, «La educación superior en México», Mirada legislativa, núm. 83, 2015.

${ }^{10}$ Cuba está a la par de los países desarrollados con las tasas más altas, como Corea o Finlandia (95 y 94 por ciento, respectiva-
}

El recetario neoliberal es claro, ofrecer mano de obra barata a los capitales conectados a los circuitos de exportación y desvincular a la mayoría de los trabajadores de relaciones salariales formales, sin importar la degradación social. En ese sentido, también se desvaloriza el sistema universitario debido a la política neoliberal de recortar el presupuesto, no abrir nuevas universidades y no ampliar la matrícula. Como resultado, la educación superior se torna muy selectiva: siete de cada 10 personas de 19 a 23 años no tienen acceso a las universidades y se integran a la sobrepoblación, una masa desbordante de trabajadores obligados a laborar en condiciones muy precarias o a emigrar.

Para saldar la deuda social en educación superior se requiere una política que garantice a los egresados de bachillerato el acceso pleno a las universidades y así sucesivamente en los grados previos.

\section{Estándares internacionales y decrecimiento}

Con la intención de subir los estándares internacionales, el actual gobierno pretende alcanzar la cobertura de 40 por ciento en educación superior para 2018 (aún por debajo del promedio de América Latina) ${ }^{11}$ y ampliarla a 48 por ciento en 2020 (todavía debajo de los siete países latinoamericanos con mayor cobertura). Dicho cometido requiere una mayor inversión con la finalidad de ampliar el sistema de educación pública superior, la capacidad docente y la infraestructura para atender a los estudiantes. ${ }^{12}$ No obstante, el régimen de

mente). Organización de las Naciones Unidas para la Educación, la Ciencia y la Cultura (UNESCO), Informe regional Educación para todos, Santiago, UNESCO, 2011.

${ }^{11}$ Lilian Hernández, «Meta corta en educación superior, opinan rectores», Excélsior, 8 de junio de 2013.

${ }^{12}$ Según las estimaciones oficiales, para lograr la meta de 40 por ciento, es indispensable el incremento anual de un millón de estudiantes, de los cuales 700 mil corresponden a escuelas públicas. Enrique Peña Nieto, II Informe de gobierno, 2014, http://www.presidencia.gob.mx/segundoinforme/. Con el 
«austeridad» está obsesionado en recortar el gasto público en educación y desarrollo social, para aumentar las partidas de pago a la deuda externa y el respaldo a grandes empresas. Con dicha política se pretende impulsar, poco a poco, el mercado de servicios educativos, sin importar que la deuda social se acreciente.

A las universidades se les exige elevar la matrícula, pero ese requerimiento no se acompaña de un aumento proporcional y suficiente de recursos financieros. En efecto, en los últimos cinco años la tendencia ha sido a la baja, con afectación directa a la calidad educativa. Pero más allá de la restricción presupuestal, las universidades públicas han incrementado la matrícula, aunque limitadamente, para ofrecer estudios superiores a estudiantes que de otra forma estarían condenados a subsumirse en los pantanos de la exclusión social y terminar por ser motejados cínicamente como «ninis». Es sintomático que el gasto en educación superior no corresponda con el aumento observado en la matrícula ni soporte el aumento sustancial de la cobertura para alcanzar los estándares internacionales. Con menos dinero, han absorbido el incremento de estudiantes, lo cual redunda en múltiples carencias.

Pese a los magros presupuestos, y en gran medida gracias al esfuerzo de los profesores universitarios, en las últimas dos décadas la oferta educativa ha registrado un cierto aumento, sobre todo en el sector público, que explica 70 por ciento de tal crecimiento en planteles y

interés de conseguir la meta de 48 por ciento de cobertura, tendrían que incluirse a, por lo menos, un millón de jóvenes en el sector público y 500 mil en el privado. En adición, se precisaría una inversión anual de 7 mil millones de pesos, que tendría que mantenerse o elevarse en los siguientes siete años. Rodolfo Tuirán, «La educación superior en México: avance, rezagos y retos», 2011, http://online.aliat.edu.mx/adistancia/Calidad/ unidad4/lecturas/txt_1_s4_educ_sup_avan_rez_ret_tuiran.pdf. Sin embargo, durante el sexenio del panista Felipe Calderón el gasto en educación bajó de 6.5 a 6.4 por ciento, 1.6 puntos debajo de 8 por ciento establecido en La Ley General de Educación. Rodolfo Tuirán, «La educación superior en México...». De persistir el actual esquema de financiamiento, la meta será imposible de cubrir. cobertura efectiva. Empero, el crecimiento en la matrícula universitaria es contradictoria, carece de soportes financieros y se sostiene en la infraestructura existente y los mismos equipos docentes; excluye a nuevas camadas de estudiantes y propicia tensiones institucionales, pero significa un esfuerzo inacabado de inclusión educativa. En la medida que sólo tres de cada 10 jóvenes de entre 19 y 23 años tienen la oportunidad de cursar una carrera y alrededor de siete millones no pueden prepararse, resulta evidente que la responsabilidad no puede recaer sólo en las instituciones educativas, sino principalmente en el Estado omiso.

\section{Clasismo educativo}

La gran diferenciación social en México permite que las elites compuestas por la alta burocracia, los líderes de la clase política, los gobernantes y los empresarios favorecidos por el gobierno perciban grandes ingresos y se den el lujo de enviar a sus hijos a las consideradas las mejores universidades del mundo, donde se cobran altas cuotas de ingreso, colegiaturas y otros gastos educativos y de manutención. De igual modo, en el país existen universidades y tecnológicos de elite para las clases sociales potentadas, en las que también se pretende formar a la clase dirigente. Los grandes empresarios extraen abultadas ganancias, la alta burocracia accede a sueldos elevados, sobresueldos y compensaciones, además de que cubren gastos ordinarios con cargo al erario y disponen de prestaciones y acceso preferencial a becas, lo que hace posible que realicen un considerable gasto educativo en universidades privadas, extranjeras o nacionales.

En contraste, las clases populares perciben bajos salarios y son afectadas, de manera creciente, por la política de rechazo a estudiantes en las universidades del país, lo cual es expresión del clasismo imperante. La exclusión busca justificarse con un proceso de selección 
basado en la aplicación del examen de admisión, en el que el aspirante que no demuestre poseer la calidad suficiente estará fuera del proceso educativo. ${ }^{13}$

Más que una selección de estudiantes en los programas educativos, el examen convalida la exclusión, que tiende a ser clasista, puesto que los sectores populares resultan mayormente rechazados; provienen, en mayor medida, de clases sociales y familias despojadas, explotadas y discriminadas (hijos de obreros, campesinos, desempleados, migrantes, madres solteras, etcétera). ${ }^{14}$

El problema es que en la práctica la educación no se considera un derecho, como pudiera colegirse de la carta constitucional, sino un privilegio para quienes tienen suficiente «calidad» académica, a menudo heredada de la ubicación en la estructura social. Las consecuencias para los rechazados son severas: en principio son considerados como estudiantes insuficientes, fallidos, según el vocabulario de la Evaluación Nacional del Logro Académico en Centros Escolares (ENLACE). Los medios de comunicación los presentan como «reprobados» y a quienes se movilizan en defensa de la educación pública gratuita como «anarquistas», revoltosos, vándalos y demás calificativos. El cierre del sistema educativo se complementa con un mercado laboral estrecho, excluyente y precarizado. De tal suerte que quienes son negados por la educación y el trabajo reciben la impronta clasista de «ninis».

\footnotetext{
${ }^{13}$ El proceso de selección consiste en la aplicación de un examen de 120 preguntas. Uno de cada diez aspirantes es aceptado y el resto buscará otras opciones - por ejemplo en universidades privadas de baja calidad - o simplemente aceptará su exclusión del sistema. En las minucias de la selección de aspirantes el asunto se torna peliagudo si se considera que el contestar de modo equivocado una pregunta podría implicar ser aceptado o rechazado, dado el esquema de competencia fijado desde el principio para acceder a la universidad.

${ }^{14}$ Por su magnitud, el ejemplo más evidente es la Ciudad de México, la urbe concentradora de recursos y de problemas, donde cada año más de 200 mil jóvenes son rechazados de las universidades. Rubén Martín, «El drama de los rechazados», El Economista, 6 de agosto de 2013.
}

\section{Ingeniería social: conversión del «bono demográfico» en «precariado»}

La categoría social más afectada por la política educativa restrictiva y la política laboral precarizante es la juventud de las clases populares. El discurso habitual suele idealizar a la juventud como el futuro de la sociedad, sin hacer distinciones sobre su diferenciación social. Representa un recurso humano, un potencial productivo de la economía nacional. En esa lógica, la abundancia de jóvenes es un componente esencial del «bono demográfico», cuando la población en edad de trabajar (jóvenes y adultos) supera a la población dependiente (niños y adultos mayores). Sin embargo, en México hay una fractura y despilfarro de dicho bono porque no existen fuentes ocupacionales formales, seguras y de calidad, en especial para los jóvenes.

A México se le considera un «país joven» con un crecimiento del bono proyectado hasta 2025. ${ }^{15}$ En la realidad, los jóvenes conforman el sector que padece los mayores grados de exclusión laboral: la tasa de desempleo juvenil duplica el desempleo general de 5 por ciento. El «bono demográfico» es dilapidado con 20 por ciento de jóvenes que carece de acceso a la educación y al trabajo formal, y la mayoría de los excluidos son mujeres (75 por ciento), sea por discriminación o por dedicarse al cuidado de la familia. Los jóvenes excluidos encuentran «válvulas de escape» en actividades degradadas y peligrosas (economía informal, migración y delincuencia).

En ese escenario abundan explicaciones que arremeten contra el sistema de educación pública como causante de la exclusión laboral. Muestra de ello es el argumento de la Organización Internacional del Trabajo (ОIT) sobre el desempleo juvenil en México y el mundo, que entre otras razones parece obedecer a la «falta de vinculación

${ }^{15}$ En el país viven 31.4 millones de jóvenes de 15 a 29 años, que representan 26.3 por ciento de la población. 
entre universidades, fábricas y centros de trabajo», por lo que se promueven los «modelos de formación con un alto contenido práctico», como la profesionalización de los jóvenes mediante la «formación dual». Ésta consiste en programas educativos en los cuales los jóvenes estudian y al mismo tiempo entran al mercado laboral a modo de prueba; el objetivo es aplicar los conocimientos en las empresas por tres años, sin tratarse de servicio social o prácticas profesionales. ${ }^{16}$ Así, se perfila una fuerza de trabajo joven y abundante, precarizada desde el primer empleo, sin experiencia sindical y dispuesta a aceptar empleos de bajos salarios y temporales.

\section{Precarización}

Hacia fuera y hacia adentro, la precarización envuelve el trabajo universitario. Cada vez más, los trabajadores del conocimiento formados en los recintos universitarios son subsumidos por el capital. Científicos, tecnólogos y profesionistas encuentran empleos con bajos salarios en proporción a su formación académica o realizan actividades en las que no gozan de autonomía, como otrora sucedía con las profesiones liberales, los investigadores y los científicos. En particular, los jóvenes universitarios encuentran puestos de trabajo temporales, inseguros y mal pagados.

Los trabajadores académicos también resienten el deterioro de las condiciones de trabajo: disminución del valor de los salarios y prestaciones, contratos temporales y precarios, amén de que el ámbito de trabajo se deteriora por la insuficiencia de recursos para dotar de infraestructura, equipamiento, materiales y recursos pedagógicos suficientes en el desempeño de la labor docente. Se está generalizando la figura de profesores precarizados, que carecen de contra-

${ }^{16}$ María del Pilar Martínez, «Nuevos modelos de educación para reducir el desempleo juvenil: OIT», El Economista, 22 de marzo de 2015. to de tiempo completo o teniéndolo afrontan el deterioro de salarios y prestaciones. Al despojo de derechos laborales se agrega una precarización pedagógica en la medida en que profesores e investigadores se asumen como una suerte de técnicos de la enseñanza y el conocimiento que se limitan a transmitir información y datos para formar estudiantes según un menú acotado de capacidades y competencias profesionales con enfoques disciplinares estrechos. No se conciben como intelectuales y pensadores críticos que buscan tener un amplio bagaje cultural, preocupados por formar estudiantes con visiones críticas, creativas y propositivas desde visiones amplias del mundo actual.

Garantizar el acceso de los jóvenes a la educación superior no sólo es un asunto de financiamiento e infraestructura, también precisa de una mayor plantilla de personal docente que cuente con capacidades científicas, intelectuales y didácticas, además de aptitudes críticas y creativas para impartir y promover una educación de calidad, ${ }^{17}$ lo cual requiere que disponga de condiciones de trabajo dignas.

\section{Epistemicidio}

Una tendencia es que la ciencia está siendo determinada por la exigencia de que el capital obtenga ganancias. Ciertos temas son investigados con el propósito de solucionar problemas específicos con tecnologías acordes que producirán mercancías, las cuales arrojarán beneficios a las empresas. Las necesidades sociales que no sean rentables resultarán despreciadas. Hasta las ciencias más abstractas (por ejemplo,

\footnotetext{
${ }^{17}$ En México, la mayoría de los profesores de las universidades públicas (60 por ciento) están contratados por hora clase o a tiempo parcial. Véase Asociación Nacional de Universidades e Instituciones de Educación Superior (ANUIES), «Los profesores de tiempo parcial en las universidades públicas mexicanas: elementos para un diagnóstico. Reporte Ejecutivo», Consejo de Universidades Públicas e Instituciones Afines, 2015. Por tal razón, deben trabajar en otras actividades para complementar sus ingresos, como impartir clases en otras escuelas, hacer consultorías, asesorías, laborar en el gobierno o en actividades.
} 


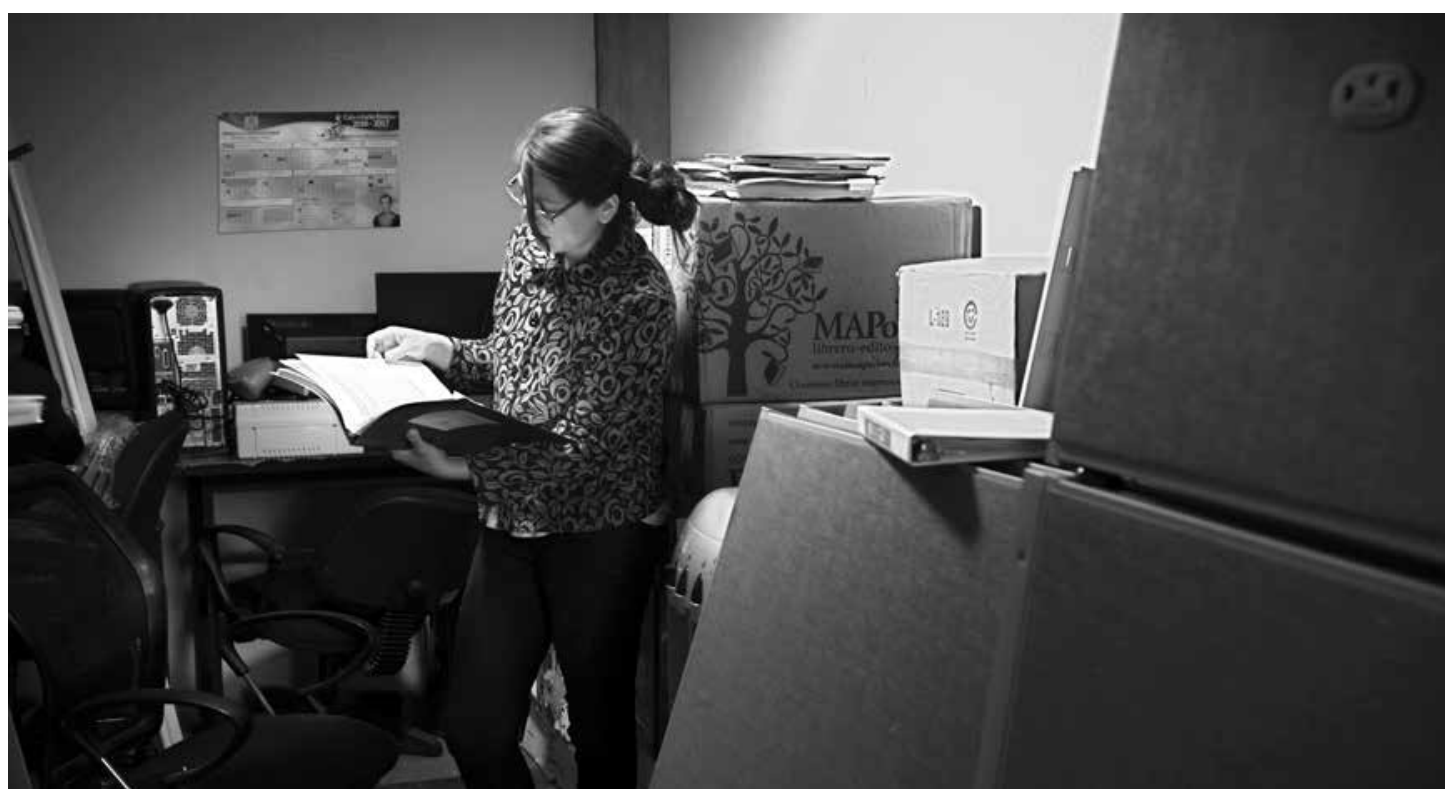

Los trabajadores académicos también resienten el deterioro de las condiciones de trabajo: contratos temporales y precarios, disminución del valor de los salarios y prestaciones, amén de que el ámbito de trabajo se deteriora por la insuficiencia de recursos. Fotografía: Carlo Román

las «ciencias duras») son determinadas por el mercado y las ciencias sociales se abocan a justificar el sistema en el plano económico, jurídico, político e ideológico. De manera reiterativa, destacan las ciencias y formas de pensamiento convencional que sustentan y justifican el sistema dominante, como el neoclasicismo y el neoliberalismo en la economía.

Nuevas teorías, hipótesis e investigaciones se precisan para estudiar problemas encaminados a las necesidades radicales de la población y la construcción de un sistema más justo. La ciencia, la ética, la filosofía, la literatura y otras formas de pensamiento, análisis y reflexión pueden estar imbuidas de una criticidad necesaria. El pensamiento crítico ha generado ideas, conceptos y argumentos sobre la economía política que han develado la lógica del capital. Desde esa orientación puede nacer una conciencia crítica y una praxis social transformadora.

La negación de las formas de pensamiento propio, de las culturas ancestrales y de las expresiones críticas se configuran como una suerte de epistemicidio. ${ }^{18}$ La tónica es repetir

\footnotetext{
${ }^{18}$ Santos Boaventura de Sousa, Descolonizar el saber, reinventar el poder, Montevideo, Trilce, 2010.
}

la ciencia y la teoría provenientes de los centros dominantes. Una salida es la tentativa de la descolonización epistemológica.

\section{Cobranza}

Al ser organismos descentralizados del Estado, sujetos a la norma constitucional, las universidades públicas deben ser gratuitas y no exigir pagos a los estudiantes. Más aún, no deben ser instrumentos que impongan criterios clasistas de selección y que reproduzcan las desigualdades sociales. El cobro de cuotas y colegiaturas niega el acceso a las universidades a un sector muy vasto de un país afectado severamente por la pobreza. ${ }^{19}$ Es evidente que la puerta de acceso y permanencia resulta excluyente al aplicar exámenes de selección y al cobrar colegiaturas, cuotas y servicios administrativos, lo cual redunda en una lógica de contención clasista.

${ }^{19}$ Según Julio Boltvinik, en México hay cien millones de pobres, es decir, 84.3 por ciento de la población. Julio Reyna, «Cien millones de mexicanos en la pobreza, afirma Julio Boltvinik», La Jornada, 22 de julio de 2015. Según datos oficiales, 55.3 millones (46.2 por ciento) son pobres. Consejo Nacional de Evaluación de la Política de Desarrollo Social (Coneval), Medición y Análisis de la Pobreza en México 2006-2015, México, Coneval, 2015. 
Las universidades se sostienen con los impuestos, si bien los presupuestos educativos de los gobiernos neoliberales se recortan de forma alevosa siguiendo criterios tecnocráticos «financiaristas» que atentan contra las necesidades sociales. La reducción del presupuesto educativo, la selección de estudiantes y la petición de cuotas significan un desacato de la norma constitucional, contravienen el desarrollo humano y son fuente de grandes conflictos.

El cobro de cuotas y colegiaturas ha sido cuestionado por movimientos estudiantiles, como el Consejo Nacional de Huelga de la Universidad Nacional Autónoma de México (UNAM) que en 1999-2000 logró revertir el cobro de inscripciones, cuotas y servicios. Recientemente, se presentó el caso de una estudiante de la Universidad Michoacana de San Nicolás de Hidalgo que a título individual solicitó un amparo contra las cuotas en esa institución. En la Suprema Corte el ministro conservador Jorge Pardo Rebolledo argumentó en contra del amparo al declarar que la constitución «señala que el Estado no está obligado a impartir educación gratuita» 0 que la gratuidad sólo procede «en lo referente a la educación obligatoria». ${ }^{20}$ No obstante, el artículo tercero, fracción IV, expone: «Toda la educación que el Estado imparta será gratuita». Asimismo, el ministro sostuvo que las universidades autónomas cuentan con «libertad patrimonial» para solicitar cuotas o colegiaturas y que las universidades autónomas «al no ser parte del Estado, están en su derecho de imponer diversos cobros a sus estudiantes». ${ }^{21} \mathrm{Al}$ final de cuentas, la Corte resolvió otorgar el amparo para que se le otorgue educación superior gratuita, pero dicha resolución sólo se aplica a favor de la demandante y no se hace extensiva a la comunidad de estudiantes.

${ }^{20}$ Jesús Aranda, «Universidades no están obligadas a dar educación gratuita: ministro», La Jornada, 13 de enero de 2016.

${ }^{21}$ Humberto Musacchio, «Cuotas en las universidades, otra vez», Excélsior, 14 de enero de 2016.

\section{Segregaciones}

Al amparo de la astringencia financiera, los gobiernos no invierten en la creación de nuevas universidades ni en la ampliación de las existentes en desdoro de garantizar la educación que demanda la población. Con el pretexto de la austeridad se utilizan criterios inequitativos para asignar el de por sí insuficiente subsidio, por lo que se reproducen dinámicas de desarrollo geográfico desigual: las universidades grandes, consideradas «nacionales», a la sazón ubicadas en la capital del país, cuentan con mayor capacidad de negociación política y concentran el presupuesto; en tanto, la mayoría de las pequeñas universidades «estatales» se disputan el resto del pastel presupuestal, sin posibilidades reales de crecimiento. La contravención del federalismo fiscal impide la descentralización de la vida educativa nacional.

La asignación de montos se fija según el promedio de estudiantes, lo que reproduce el círculo vicioso de concentrar el presupuesto en las grandes que poseen más estudiantes y de restringirlo entre las pequeñas con menos estudiantes. Lo anterior perpetúa la imposibilidad estructural de cumplir la misión educativa y de crecer acorde a las demandes del entorno.

$\mathrm{Al}$ respecto, las desigualdades de cobertura educativa en las universidades están muy acentuadas en el país. En primer lugar se posiciona la Ciudad de México, donde se ubican universidades y tecnológicos considerados nacionales, grandes y con mayor presupuesto, con una cobertura de 74 por ciento, en segundo plano le siguen Nuevo León (41.7), Sinaloa (40.5) y Sonora (40.3); en el otro extremo se encuentran las entidades con mayor nivel de pobreza y rezago educativo: Chiapas (15.6), Oaxaca (17.6), Guerrero (17.8) y Guanajuato (21.2). ${ }^{22}$

Las universidades estatales presentan un panorama contable resquebrajado. El recuento de

${ }^{22}$ Senado de la República, op. cit. 
los daños recuerda un corte de caja con saldos rojos, como si la función primordial de las universidades públicas fuese hacer un balance fiscal anualizado entre ingresos y egresos. Endeudamiento y recortes presupuestales cimbran los cimientos institucionales. Desde esa exigencia, varias universidades están en capilla.

Como respuesta, las autoridades hacendarias y universitarias pactan planes de ajuste que significan el deterioro de la institución y la claudicación de la misión educativa, al punto en que el pago de nómina y prestaciones se convierte en la preocupación principal de los rectores de las universidades castigadas. ${ }^{23}$ Caso contrario es cuando las comunidades universitarias se movilizan para resistir la política restrictiva. En esas circunstancias la insuficiencia de fondos públicos ha propiciado el enfrentamiento político entre rectores y gobernadores.

De forma cíclica padecen la amenaza de caer en bancarrota, a no ser que acepten reconvertirse en instituciones real o virtualmente privatizadas. El trato diferenciado imposibilita la unidad estratégica de las universidades públicas en torno a un verdadero proyecto educativo nacional, amén de que no existe una

\footnotetext{
${ }^{23}$ En la actualidad, entre los casos más complicados se hallan la Universidad Veracruzana con un déficit de 2 mil 300 millones de pesos, la Universidad de Baja California Sur con un adeudo de 470 millones y la Universidad Autónoma de Morelos con 400 millones. Sonia Del Valle, «Arrecian las crisis en las universidades», Reforma, 31 de octubre de 2016. Las retenciones y los recortes afectan a la Universidad Autónoma de Zacatecas (UAZ), con una retención de 136 millones de pesos en participaciones, y la Universidad Autónoma de Querétaro (UAQ), con un recorte de 22 millones. Claudia Solera, «Peligran pagos y salarios de las universidades; la de Zacatecas cubrió parte de la deuda con edificios», Excélsior, 24 de noviembre de 2016; Omar Hernández, «Adeudo fiscal deja insolvente a la UAZ», Excélsior, 13 de octubre de 2016; Viviana Estrella, «Recortan 22 mdp de fondo a la UAQ», El Economista, 12 de marzo de 2015. La Universidad Intercultural de Chiapas sufrió una reducción de 6 millones de pesos, lo que provocó el despido de maestros, quienes hicieron reclamos al Congreso local para la restitución de 47 millones de pesos con los que operaba la institución. Elio Enríquez, «〈Toman〉 unidad de Universidad Intercultural de Chiapas; rechazan despidos», La Jornada, 23 de agosto de 2016.
}

Cobertura educativa en las universidades
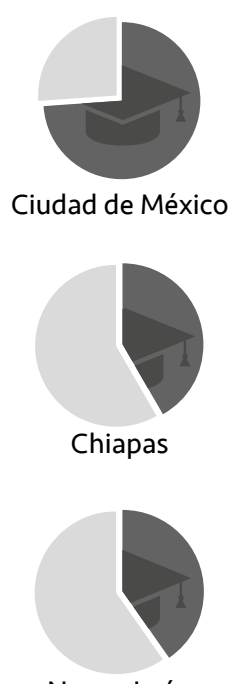

Nuevo León

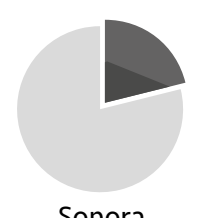

Sonora

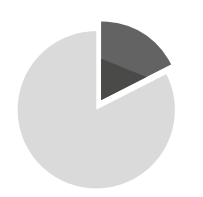

Guanajuato

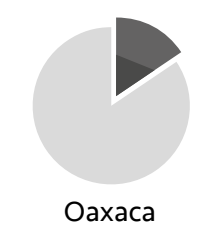

La asignación de montos se fija según el promedio de estudiantes, lo que reproduce el círculo vicioso de concentrar el presupuesto en aquellas con mayor matrícula y de restringirlo entre las pequeñas. legislación nacional que garantice el financiamiento y desarrollo de la universidad pública. Tampoco las instancias de representación cumplen el papel de defender el interés colectivo, es el caso de la Asociación Nacional de Universidades e Instituciones de Educación Superior (ANUIES) o el Consorcio de Universidades Mexicanas (Cumex), pues respaldan enfoques elitistas y competitivos bajo la prédica de la educación de calidad a tono con las pautas del mercado.

Esta directriz institucional se refuerza con la dinámica inercial de gestión política condicionada del presupuesto. En cada año fiscal las universidades con problemas presupuestales están condenadas a perpetuar su crisis de insolvencia en detrimento de la calidad educativa y a negociar de modo subordinado la supervivencia institucional con las autoridades hacendarias y parlamentarias.

\section{Capitalismo cognitivo}

El fin supremo de generar ganancias superlativas mediante la renta tecnológica inunda el trabajo académico y científico y se impone a la necesidad de constituir un basamento del desarrollo humano con el propósito de satisfacer las necesidades básicas de la población. La idea de que el conocimiento y la enseñanza también son mercancías se introduce en la formación de estudiantes desde principios pedagógicos derivados de la competencia, en tanto que los científicos, las agendas de investigación y sus frutos están condicionados por los esquemas de financiamiento, la mercantilización y los sistemas de patentes.

Sin embargo, la inversión del Estado en educación superior y en investigación y desarrollo es crucial para alentar la producción científica y tecnológica. La generación de conocimiento, la formación de personal de alto nivel de calificación, la publicación de resultados y el patentamiento de innovaciones son 


\section{En México, cada año se gradúan apenas entre $\mathbf{3}$ mil y $\mathbf{4}$ mil doctores; mientras que en Estados Unidos, alrededor de $\mathbf{6 0}$ mil.}

requerimientos de un mundo ferozmente competitivo e interconectado por múltiples redes de capital monopolista.

Es indispensable la masa crítica de investigadores para crear conocimientos, productos, métodos o sistemas de acuerdo con un cierto modelo de desarrollo nacional. México cuenta con un personal insuficiente para afrontar ese reto: apenas 386 investigadores por cada millón de personas. ${ }^{24}$ En México la inversión en ciencia y tecnología es insuficiente, oscila entre 0.20 y 0.38, entre 2005 y 2013, muy lejos de la promesa oficial de arribar a 1.0 por ciento, muy atrás de los parámetros internacionales. ${ }^{25}$

Las universidades mexicanas no disponen de la capacidad suficiente para formar doctores en las diversas ramas del conocimiento. ${ }^{26}$ Cada año se gradúan apenas entre 3 mil y 4 mil doctores en México, mientras que en Estados Unidos, país con el cual se compite de manera frontal, lo hacen alrededor de $60 \mathrm{mil}$; sin contar que una porción importante de doctores mexicanos emigra al vecino país del norte bajo la tónica de «fuga de cerebros», rubro en el cual México

\footnotetext{
${ }^{24}$ Muy lejos de Finlandia (7 mil 482 por cada millón de habitantes), Islandia (7 mil 12) y Dinamarca (7 mil 730). En América Latina, Brasil encabeza la lista con 710 por millón de habitantes y México se halla en segundo lugar. Organización para la Cooperación y el Desarrollo Económicos (OCDE), op. cit.

${ }^{25}$ Organización de las Naciones Unidas para la Educación, la Ciencia y la Cultura (UNESCO), Informe de la UNESCO sobre ciencia. Hacia 2013, París, UNESCO, 2015.

${ }^{26}$ En términos acumulados, para la formación de estudiantes universitarios, de donde a la postre egresarán investigadores y científicos, México se ubica en el penúltimo lugar de la OCDE, después de Turquía, por su bajo gasto. En ese rubro, Dinamarca invierte más: en 5.2 años gastó 110 mil 520 dólares; mientras que en 3.3 años México gastó 26 mil 428 dólares. En la carrera de un universitario, México gasta la misma cantidad que Estados Unidos en un solo año. Organización para la Cooperación y el Desarrollo Económicos (OCDE), op. cit.
}

ocupa el sexto lugar como exportador de personal calificado. ${ }^{27}$

En las distintas ramas de la ciencia la producción cognitiva que se publica en textos académicos conforma un referente del desempeño de los investigadores. En la bibliometría internacional México ocupa un lugar marginal. ${ }^{28}$ Respecto al número de patentes, México representa sólo 0.1 por ciento de las solicitudes en el mundo. ${ }^{29}$

\section{Condicionamiento externo}

La continua evaluación de programas y académicos para establecer jerarquías y condicionar el acceso a recursos, además de la política de astringencia financiera para el sector educativo, propician una reestructuración de facto de la universidad pública. Por insolvencia presupuestal, diversas actividades son desincorporadas en detrimento de la enseñanza, la investigación y la vinculación con la sociedad, en tanto que se alienta la venta de servicios y el financiamiento externo de instancias privadas (fundaciones, bancos y empresas). Lo público se deslava y adquiere tonalidades privativas; la educación superior avanza por la senda de la privatización.

Los políticos y la burocracia que imponen la política fiscal obstruyen, retienen o condicionan la entrega de recursos suficientes para el buen funcionamiento de las universidades. Ello en un marco donde prevalece la carencia de leyes y reglas claras que garanticen la provisión completa y oportuna de los recursos. Incluso si fueran aprobados adecuadamente por el Congreso,

\footnotetext{
${ }^{27}$ Raúl Delgado Wise, «Migración mexicana altamente calificada: problemática y desafíos», Observatorio del Desarrollo. Investigación, reflexión y análisis, vol. 2, núm. 8, 2013.

${ }^{28}$ Estados Unidos encabeza la numeralia con 208 mil 601 textos en 2011, le siguen China con 89 mil 894 y Japón con 47 mil 106. Brasil encabeza la producción científica en América Latina con 13 mil 148 textos. México tiene una posición mundial marginal con 4 mil 128, por encima de Argentina, 3 mil 863. Banco Mundial, World Development Indicators 2014, Washington, Banco Mundial, 2014.

${ }^{29}$ Organización de las Naciones Unidas para la Educación, la Ciencia y la Cultura (UNESCO), Informe de la UNESCO...
} 
cuando entran en las arcas del Estado suelen ser retenidos y en consecuencia la entrega a las universidades se demora.

La insolvencia financiera decretada por las autoridades hacendarias pone en predicamento el trabajo educativo de las universidades estatales, que se ven forzadas a negociar la restitución de fondos a cambio de implementar programas de «austeridad» y reestructurar su funcionamiento con medidas draconianas que comprenden precarización laboral, exclusión de estudiantes, cobro de cuotas y servicios, entre otros.

En cualquier caso, los recursos públicos destinados a las universidades son notoriamente insuficientes, ya que no responden a la necesidad de inclusión educativa de los jóvenes ni mantienen en buen estado el funcionamiento de las universidades. El financiamiento a la educación superior no permite elevar la matrícula en la medida demandada por la población escolar.

El Estado no dispone de una política de financiamiento sistemática y coherente, y obliga a las universidades a concursar por los fondos. En efecto: un área de especialización de la burocracia universitaria y de los investigadores es «bajar» recursos públicos y privados para financiar actividades y proyectos. En una situación de astringencia es recurrente que el financiamiento «extraordinario» se utilice en construcciones, ampliaciones o adquisición de equipo. Si en los siguientes ejercicios presupuestales ya no se reciben esos recursos, el déficit financiero aumenta y se pierden los medios para dar mantenimiento adecuado a las instalaciones o al equipamiento adquirido en épocas de «vacas gordas».

\section{Rectorado}

A partir de 1997 comenzó a deteriorarse la vetusta hegemonía política del Partido Revolucionario Institucional (PRI) que controlaba todos los hilos de la política nacional, hasta que en 2000 perdió provisionalmente la presidencia para concederla a su aliado, el Partido Acción Nacional (PAN), que continuó aplicando el mismo proyecto neoliberal. En algunas esferas, sobre todo locales, sucedieron pequeños cambios políticos, por ejemplo en las formas en que se negociaba con las instancias federales y se alcanzaban acuerdos. Las nuevas coordenadas políticas permitieron que, hasta cierto punto, los rectores de las universidades dejaran de estar supeditados a los gobernadores y al partido en el poder. El aparente desapego entre rectores y gobernantes creó la posibilidad de que los primeros se expresaran de manera pública sin tantas restricciones y que realizaran gestiones con distintos partidos políticos y líderes parlamentarios. Al mismo tiempo se desataron disputas políticas entre ambas figuras a causa de la problemática universitaria, con escenarios de confrontación manifestados recientemente en Veracruz y Morelos. La cuestión es que el conflicto se administra y posterga sin ofrecer soluciones de largo aliento.

El rejuego político del presupuesto universitario se presta al protagonismo de la clase política y a gestiones de ocasión de los rectores. Ante los presupuestos raquíticos, los diputados suelen presentarse como los salvadores que «enmiendan la plana» al Ejecutivo en el presupuesto federal. Aunque esos incrementos son variables, dependen de cada una de las instituciones federales y los fondos asignados a las universidades estatales, tecnológicas y politécnicas, ya que no todas reciben la misma cantidad. Cada año los rectores tienen que negociar mayores recursos con el gobierno del estado, la SEP, la Secretaría de Hacienda y los diputados locales, a fin de solventar las necesidades mínimas.

\section{Conflictividad}

Mientras que en la educación básica se aplica una reforma cuyo propósito es modificar las relaciones laborales con el uso de instrumentos 


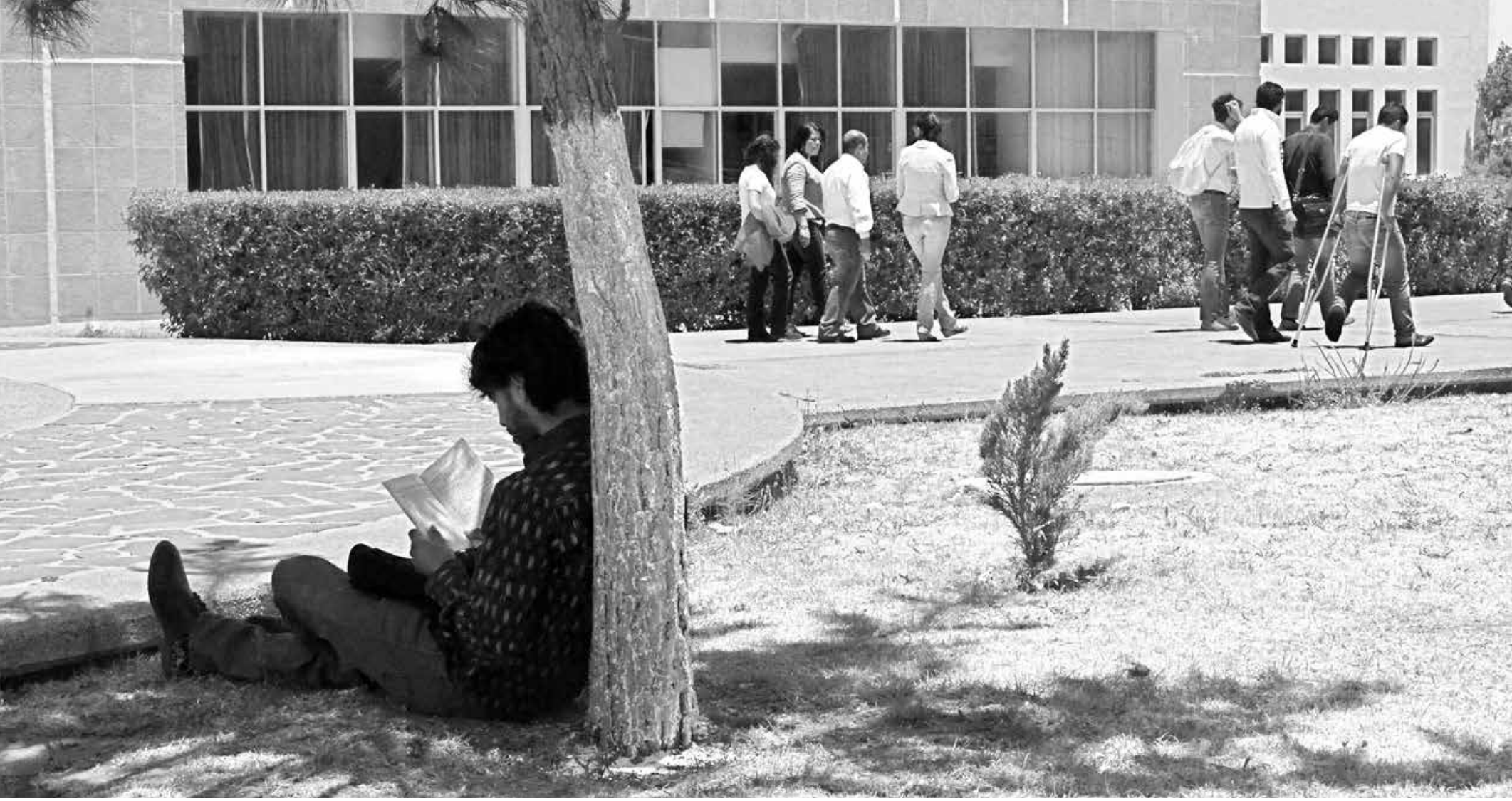

El problema de evaluación estandarizados -que incendel rechazo a estudiantes que intentan ingresar en las universidades también se presenta en instituciones grandes y pequeñas.

tivan la inseguridad laboral al promover el despido libre y el ataque a las expresiones de sindicalismo independiente mediante el encarcelamiento de líderes y la represión de las movilizaciones magisteriales-, en la esfera de la educación superior se implementa el desfinanciamiento, la precarización laboral y la mercantilización de la educación. La aplicación de políticas antilaborales y desfinanciadoras orquestada desde la alta burocracia gubernamental y respaldada por los líderes parlamentarios se ejecuta de manera diferenciada, con distintos tiempos y movimientos, para propiciar una fragmentación del sector educativo por niveles educativos, regiones, sindicatos e instituciones particulares.

Un detonador eficaz de los conflictos dentro de las universidades, que debilita su gobernabilidad, es el recorte de recursos financieros como preámbulo para el condicionamiento a nuevos recursos, siempre que se adopten las medidas orientadas a la mercantilización de la educación. En lugar de incentivar la misión social educativa, los universitarios distraen gran parte de su tiempo y energía a resolver problemas internos y a solucionar el déficit financiero. Los grupos políticos se acusan mutuamente y el gobierno impone programas de reestructuración condicionados al otorgamiento del subsidio. El paso de la autonomía a la heteronomía implica la descomposición institucional, la configuración de bloques de poder que pactan con agentes externos del Estado y el capital, y las líneas políticas y académicas del desarrollo universitario.

\section{Movimientos estudiantiles}

Desde la década de los 1960 han surgido movimientos de estudiantes rechazados que impugnan la política universitaria excluyente y han conquistado derechos como la apertura de espacios, la exención de cuotas y el pase automático. En pleno auge del modelo neoliberal, entre los 1980 y 1990, los estudiantes lucharon contra el examen de admisión y a favor de un aumento de la matrícula. ${ }^{30}$

${ }^{30}$ Adrián Sotelo, Neoliberalismo y educación. La huelga de la UNAM a finales de siglo, México, Ediciones El Caballito, 2000. 
Después de la huelga de la UNAM en 19992000 no hubo movilizaciones. En 2005 surgieron el Movimiento de Estudiantes No Aceptados (MENA) en el Instituto Politécnico Nacional (IPN) y el Movimiento de Aspirantes Excluidos de la Educación Superior (MAES) en la UNAM y en otras universidades de la Ciudad de México. ${ }^{31} \mathrm{El}$ MAES planteaba cambios en el modelo educativo, que incluían la creación de universidades y el aumento de la matrícula.

El problema del rechazo a estudiantes que intentan ingresar en las universidades también se presenta en instituciones grandes y pequeñas. A guisa de ejemplo, las instituciones de educación superior más grandes, la UNAM, el IPN y la Universidad Autónoma Metropolitana (UAM) rechazan cada año a un promedio de 90 por ciento de los solicitantes que intentaban ingresar a la licenciatura. ${ }^{32}$ Aunque son las universidades con mayor presupuesto, no pueden cumplir a cabalidad con el cometido de brindar educación superior a la mayoría de los jóvenes solicitantes. Este esquema se reproduce en el resto de las universidades públicas, en distintas escalas y niveles.

Las movilizaciones de estudiantes y profesores responden a demandas diferenciadas y no se articulan a nivel nacional. Al igual que la mayoría de los movimientos sociales, sus logros suelen ser inmediatos, tematizados y episódicos. ${ }^{33}$ La exigencia de los estudiantes recha-

${ }^{31}$ Joel Ortega, «Universidad para todos», Memoria, núm. 259, 2016.

${ }^{32}$ La UNAM recibió 203 mil 187 solicitudes de ingreso, pero sólo aceptó a 19 mil 300 estudiantes en 2014; el IPN rechazó a más de 70 mil; y la UAM aceptó a 11 mil 911 de 86 mil 153 aspirantes. Rosalía Servín, «Rechazados por UNAM, IPN y UAM, 9 de cada 10 aspirantes a licenciatura», El Financiero, 21 de julio de 2014.

${ }^{33}$ Un grupo de estudiantes rechazados cerró las instalaciones de la Universidad Michoacana de San Nicolás de Hidalgo y obligó a la comunidad a tomar clases extramuros. Luego de casi un mes de conflicto, el movimiento estudiantil de la Universidad Intercultural de Guerrero provocó el cambio de rector. Docentes de la Universidad Pedagógica de Sinaloa demandaron la renuncia del rector y la reinstalación de cinco profesores removidos con 15 y 25 años de servicio. El sindicato de la Universidad Autónoma Benito Juárez de Oaxaca se apropió de las instalaciones zados en la instancia del examen de admisión se vincula a las carencias presupuestales a las que son sometidas las universidades, por lo que el requerimiento de crear más lugares para los estudiantes demandantes también entraña ampliar el número de plazas de profesores que atiendan a la creciente población escolar y, a su vez, acondicionar instalaciones y equipamiento, $\mathrm{y}$ diversificar los programas educativos.

\section{Administración de conflictos}

Ante la profundización de la política de exclusión, para los movimientos estudiantiles no es fácil mantener una lucha que debe renovarse cada año con la participación de nuevos aspirantes afectados; no obstante, han conseguido acuerdos con la Secretaría de Educación Pública (SEP) y algunas universidades con la intención de que miles de jóvenes continúen sus estudios. Al otorgar determinados lugares a los manifestantes pero sin conceder un cambio real en el modelo educativo - que incluya mayor financiamiento, la creación de universidades y la ampliación de la matrícula-, el Estado sólo administra el conflicto. La problemática es tratada como un asunto coyuntural, temporal, localizado y circunscrito al número de estudiantes movilizados; no es considerada una cuestión estructural en la que, más que acuerdos cíclicos, es menester elevar la educación al rango de derecho universal efectivo, pues no sólo es de la incumbencia inmediata de los excluidos, también alude a las comunidades universitarias y, en última instancia, al conjunto de la sociedad.

En cuestiones sociales se retrocede cuando de forma aparente se ofrecen espacios adicionales a estudiantes rechazados, pero en la realidad el derecho a la educación universitaria se dirime progresivamente mediante el estímulo a

para exigir aumento salarial y diversas prestaciones. Miguel García, «Extienden toma de universidad; movimiento de rechazados en Michoacán», Excélsior, 31 de agosto de 2016; Sonia Del Valle, op. cit. 
la competencia entre aspirantes para ocupar un espacio; de forma similar se promueve la conflictividad entre estudiantes e instituciones y la deuda social educativa cava más hondo.

Los movimientos estudiantiles han logrado que la exclusión educativa aparezca en la agenda pública, no sin soportar la metralla estigmatizadora de la mediocracia, y han colocado a estudiantes en instituciones que les negaban el acceso. En cada ciclo las universidades continúan excluyendo a miles de jóvenes al establecer cupos máximos por carrera e implementar exámenes y procesos de admisión estandarizados y orientados al precepto de educación por competencias. A la postre, la práctica institucional impone una lógica de exclusión y elitismo que contraviene la pretensión de formar nuevas generaciones de ciudadanos libres, críticos y participativos.

\section{Más allá de la coyuntura}

La pretensión oficial de ampliar la matrícula, mejorar los indicadores internacionales y responder al reclamo de los jóvenes excluidos, no puede atenderse con seriedad si no se rompe la trampa de austeridad-crisis-ajuste a la que se someten las universidades. El imperativo es recuperar la fundamentación de la reforma universitaria, emanada del «grito de Córdoba», continuada por las comunidades universitarias a lo largo de la historia, y ponerla al día para hacer de la autonomía, la libertad y el pensamiento crítico, principios creadores del quehacer educativo y la generación de conocimiento de relevancia social en consonancia con las nuevas realidades y desafíos del siglo que corre.

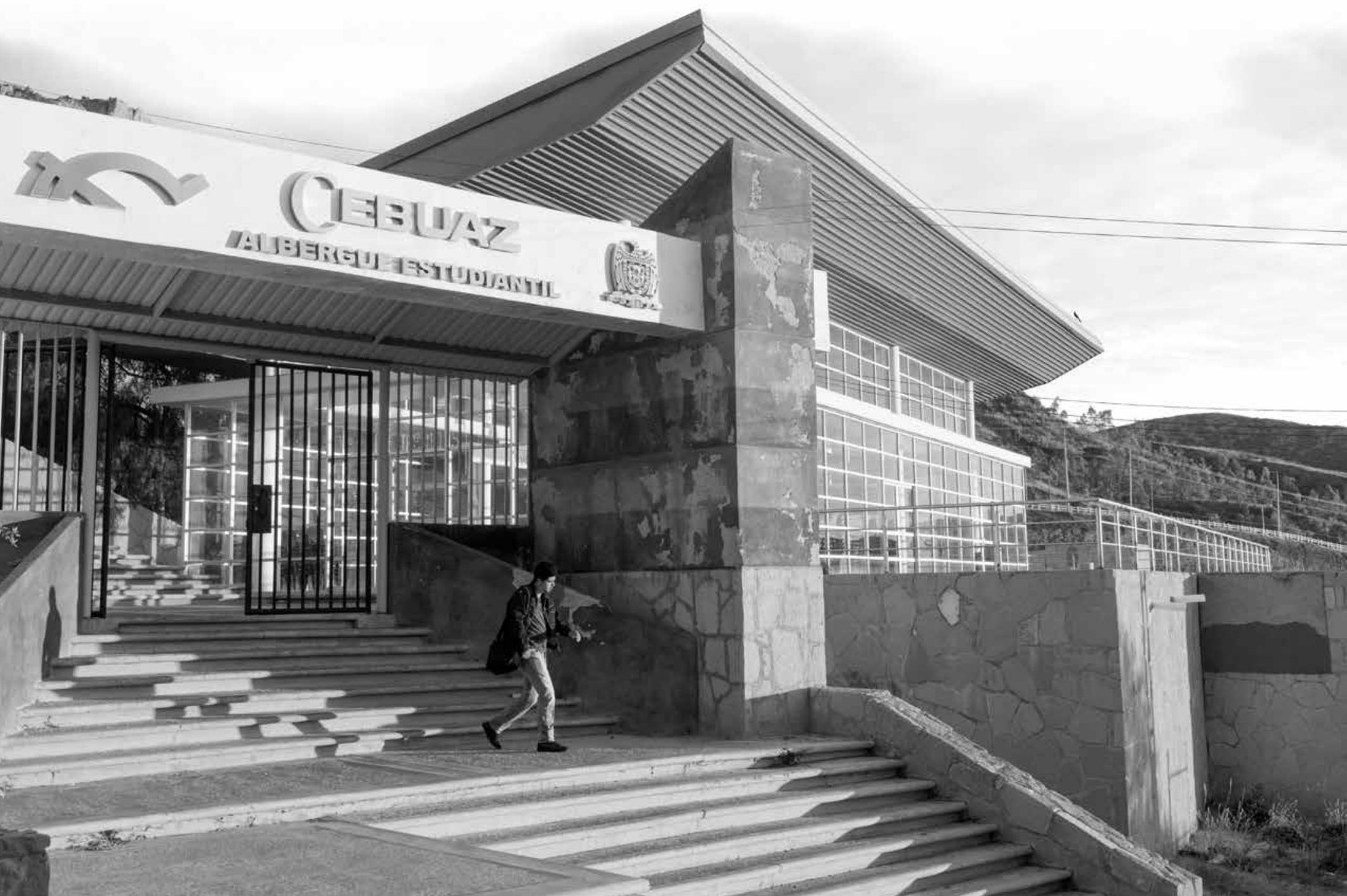

